\title{
Assessment of Western Australian sandalwood seeds for seed oil production
}

\author{
Dhanushka S. Hettiarachchi ${ }^{1,2,4}$, Yandi Liu ${ }^{1,3}$, Sonia Jose ${ }^{1}$, Michael R. Boddy ${ }^{1}$, John E.D. Fox ${ }^{3}$ and Bruce Sunderland ${ }^{1}$ \\ ${ }^{1}$ School of Pharmacy, Curtin Health Innovative Research Institute, Curtin University of Technology, Bentley, WA 6102, Australia \\ ${ }^{2}$ Wescorp Sandalwood Ltd, Canning Vale, WA 6155, Australia \\ ${ }^{3}$ Department of Agriculture and Environment, School of Science, Curtin University, Bentley, WA 6102, Australia \\ 4Email: danny@wescorp.com.au
}

Revised manuscript received 19 June 2012

\section{Summary}

The Western Australian sandalwood (Santalum spicatum R.Br.) industry is transforming into an agro-forestry industry in which the seeds are being considered as a valuable secondary incomegenerating product. Oil extracted from the seeds has a potential use in the cosmetic industry. This study aimed to identify the quality parameters for seeds to obtain oil of better and consistent quality, and the effect of seed source, seed size and storage time.

Different seed samples varied in oil content, moisture content and fatty acid profile. Larger seeds from plantation trees in the wheatbelt region of Western Australia are the most suitable source of seed oil thus far evaluated.

The seed grading system currently used by the sandalwood industry was suitable for selecting seeds from plantations (but not from natural stands in arid regions - 'wild wood') for seed oil production. Basic parameters for the selection of seeds for oil extraction were identified.

Keywords: ximenynic acid; seed oils; sandalwood; Western Australia

\section{Introduction}

The genus Santalum comprises some 25 species the natural occurrence of which extends from India to Australia and the Pacific Islands. Of the six species in Australia, five are endemic. The exception is Indian sandalwood, S. album, introduced in relatively recent times (George 1984). Western Australian sandalwood (S. spicatum R.Br.) is naturally found in most parts of Western Australia (WA). It is absent in the forests of the south-western temperate and northern tropical regions. It occurs in some relatively dry parts of South Australia (Fox 2000). Santalum species are root parasitic shrubs to small trees; they depend upon host trees for nutrition throughout their life.

Western Australian sandalwood is an important commercial timber crop. It is the source of more than half the sandalwood used globally. Its aromatic heartwood is used to produce essential oil and for other traditional uses such as agarbatti (Joss stick) manufacture and ornamental carvings. Most Western Australian sandalwood is harvested sustainably under state government supervision from natural stands (wild wood) in state forests and other reserves. Wild wood alone cannot satisfy the growing global demand for sandalwood. To meet this demand, plantations have been established by the state of WA (the Forest Products Commission, FPC) and private farmers, mostly located in the wheatbelt region of WA (Jones 2002). This area has a semi-arid climate with annual rainfall of $500-600 \mathrm{~mm}$. Sandalwood is a slow-growing tree and requires at least 20 years to yield a significant quantity of heartwood. Plantations currently provide no secondary income from agistment over these long rotations as the foliage of the trees is highly palatable and consequently subject to browsing, but their seeds have been identified as a potential source of additional income for growers.

The fruit of $S$. spicatum is a spherical (15-22 mm) drupe. The innermost kernel is white, oily and edible. This is enclosed by a smooth woody endocarp that must be broken to access the kernel. The outermost layer of the fruit is initially green and hard; on ripening this becomes brown and disintegrates on the ground after fruitfall (Fox 1992). The successful establishment of plants, fruit-bearing by 1992, allowed a comparison of the fruit from different trees. Mean quantities, mass and diameter of fruit and kernel produced on some 30 established trees in the period 1989-1992 (Barrett and Fox 1995) were observed to vary such that it was considered selection between provenances for significant traits could yield considerable improvement. Kernels were found to contain 50-60\% of lipids (Hatt 1956), and further research into this seed oil has found that it contains ximenynic acid (XYMA), a rare acetylenic fatty acid (Liu 1996).

Initial pharmacological studies of this oil revealed it produced no toxicity or pathological damage in mice, but reduced fat deposition in adipose tissue and stimulated the enzymes of lipid metabolism (Liu and Longmore 1997). Other studies of XYMA found it to alter the cytochrome P-450 enzyme in rats, indicating a pharmacological change in the hepatic metabolism (Jones et al. 1999). The ethyl ester of XYMA has been associated with microvasular kinetic properties, which could be beneficial in treatment of varicose veins (Bombardelli et al. 1994).

As global demand for novel cosmetic agents is ever increasing, sandalwood seed oil could enter the market as a cosmetic ingredient that could also act as a vehicle for other oil-soluble agents (Hettiarachchi et al. 2010). Studies continue on oxidative 
stability and pharmacological effects such as anti-inflammatory and cytotoxicity to extend knowledge of sandalwood oil as an acceptable pharmaceutical and cosmetic ingredient.

A measure of the urgency is that in the wheatbelt region of WA nearly 12000 ha are under S. spicatum plantations that could be providing around 700 tons of seeds annually. For plantation establishment, seeds are provided de-husked and sized to suit the silvicultural requirements of the purchaser. Seeds with shells are, if necessary, graded according to size and sold according to weight (McKinnell 2008). As seed production has surpassed the supply required for future plantations, seeds are now available for a second or intermediate product which could add incentive for more sandalwood planting. This would sustain and improve the sandalwood industry in WA. As the production of sandalwood seed oil evolves to a small-scale industry, the raw materials should be investigated for industrial suitability, yield and consistency of quality (Clarke 2006). Industry groups have started working with the plantation sector and small-scale farmers to establish standard procedures to collect and process seeds for oil extraction.

Our current research has the following practical goals:

- to establish selection and quality control parameters for sandalwood seeds

- to identify suitable geographic locations for plantations, optimum seed sizes and time limits for seed storage

- to identify the best-yielding, optimum-quality seed source for producing a high-grade raw material for the cosmetics and pharmaceutical industry.

\section{Methods}

\section{Plant material}

Seven samples of seeds from different geographical locations representing three regions of WA (the goldfields, the wheatbelt and the Perth region) where S. spicatum is currently found, and encompassing various seed sizes and storage times, were assembled (Table 1).

At the time of collection the outer husk (epicarp and mesocarp) had been removed from the air-dried fruit. The seeds used in this study consisted of the outer hard shell (endocarp) and the inner oil-rich kernel.
Five of the samples were from the wheatbelt region, which produces most of the commercial supplies of seeds. Of these, Samples 3, 4 and 5 from Quairading were from the same supplier and harvested in the same year, but graded differently according to the outer diameter as per plantation requirements (outer diameter is the only parameter currently considered commercially). Sample 2 was from the same location in Quairading but had been collected three years earlier and stored under atmospheric conditions.

The assembled samples were stored at Wescorp Sandalwood Ltd (WA, Australia) in cloth bags under conditions stated in Table 1. Seeds $(n=100)$ were selected randomly from the cloth bags and the axial diameter, measured using vernier callipers, and the weight were recorded before de-shelled using a size-adjustable rotary mill. Kernels were manually separated from shell fragments in a controlled storage room $\left(\sim 25^{\circ} \mathrm{C}\right)$ and stored in vacuum-sealed bags. The kernels were ground and to pass through a size 10 (1.68 mm) mesh. Weight loss on drying was determined for a representative sample from each batch using standard methods (AOCS 2009).

\section{Solvent extraction of seed oil}

The method specified by Liu et al. (1997) was used to avoid any gummy mass obtained by using the total lipid extraction method by soxhlet (Liu 1996). $n$-hexane and isopropyl alcohol (IPA) were mixed in a 3:2 ratio and nitrogen was introduced to minimise oxidation during extraction. A 10-g sample of pulverised seed kernel was dried at $40^{\circ} \mathrm{C}$ for $48 \mathrm{~h}$ in a hot room before being introduced to a $250 \mathrm{ml}$ flask, and $100 \mathrm{ml}$ of solvent mixture was added. Flasks were set on a flask shaker to operate overnight (18 h). The first extract was decanted and a fresh $100 \mathrm{ml}$ of solvent was introduced and continued in the shaker for another $8 \mathrm{~h}$. Combined solvent extracts were dried using anhydrous sodium sulphate, and flash-filtered through a column packed with inert filter medium. Extraction conditions were maintained at room temperature and protected from light. Solvents were removed by rotary vacuum evaporation (Rotavapour, Buchi, Switzerland). Residual solvents were removed by introducing nitrogen to the oil. Oils were stored in a vacuum chamber for $24 \mathrm{~h}$ before weighing. Percentage yield was determined as a weight percentage (w/w\%) from the dry weight of kernel used for extraction. Oil was stored in well-closed amber vials after filling the headspace with nitrogen.

Table 1. Collection report for seed samples

\begin{tabular}{|c|c|c|c|c|c|c|}
\hline $\begin{array}{l}\text { Region and } \\
\text { sample code }\end{array}$ & Year & Category & Appearance & $\begin{array}{c}\text { Grading } \\
\text { diameter } \\
(\mathrm{mm})\end{array}$ & $\begin{array}{l}\text { Storage } \\
\text { time } \\
\text { (months) }\end{array}$ & $\begin{array}{c}\text { Storage } \\
\text { conditions* }\end{array}$ \\
\hline \multicolumn{7}{|l|}{ Goldfields } \\
\hline Sample 1 & 2008 & Natural/wild & Rough/dark & NA & 18 & Controlled \\
\hline \multicolumn{7}{|l|}{ Wheatbelt } \\
\hline Sample 2 & 2006 & Plantation grade/commercial & Smooth / light & $>15$ & 42 & Atmospheric \\
\hline Sample 3 & 2009 & Plantation grade/commercial & Smooth yet uneven / light & $>18$ & 6 & Atmospheric \\
\hline Sample 4 & 2009 & Seconds/commercial & Smooth / light & $14-18$ & 6 & Atmospheric \\
\hline Sample 5 & 2009 & Small / commercially refused & Smooth / light/ spherical & $<14$ & 6 & Atmospheric \\
\hline Sample 6 & 2009 & Plantation collected/non-commercial & Smooth yet uneven / light & $>15$ & 6 & Controlled \\
\hline \multicolumn{7}{|c|}{ Coastal (Perth) } \\
\hline Sample 7 & 2009 & Nursery/garden & Smooth / light & NA & 6 & Controlled \\
\hline
\end{tabular}

*Controlled conditions $25^{\circ} \mathrm{C} / 50 \% \mathrm{RH}$; Atmospheric conditions $1.5-41^{\circ} \mathrm{C} / 43-63 \% \mathrm{RH}$ 


\section{Fatty acids analysis}

Fatty acids were analysed as their respective fatty acid methyl esters (FAMEs) by alkali transesterification (IUPAC 1987). Oil samples ( $0.5 \mathrm{~g}$ ) were added to screw-capped tubes and dissolved in n-hexane and reacted with $0.5 \mathrm{ml}$ of $2 \mathrm{M} \mathrm{KOH}$ in methanol. The reaction mixture was allowed to stand until two clear layers were visible. The upper solvent layer was separated and washed with water and dried over anhydrous $\mathrm{Na}_{2} \mathrm{SO}_{4}$. A 1-in-100 dilution was made with n-hexane before submitting the prepared sample to gas chromatography mass spectra (GC/MS) analysis (Christie 1993, 2007).

The GC/MS was a HP 6790 GC and HP 5971 (Hewlett Packard, CA, USA) mass-selective detector apparatus fitted with a SGE BP225 column (50\% cynaopropyl, 50\% methyl; SGE Australia). The injector temperature was $150^{\circ} \mathrm{C}, 1 \mu \mathrm{l}$ was injected splitless, flow was maintained at $55 \mathrm{ml} \mathrm{min}{ }^{-1}$, with a carrier gas of helium. The oven was started at $50^{\circ} \mathrm{C}$ and held for $2 \mathrm{~min}$, increased to $190^{\circ} \mathrm{C}$ at a rate of $8^{\circ} \mathrm{C} \mathrm{min}-1$ and then to $210^{\circ} \mathrm{C}$ at a rate of $2^{\circ} \mathrm{C} \min ^{-1}$ and held for 20 minutes. The oven - mass spectra interface was kept at $240^{\circ} \mathrm{C}$. Data analysis was by an Agilent Chemstation $^{\circledR}$ (Hewlett Packard, CA, USA) software scan method.

\section{Results}

\section{Kernel yield and seed size}

Seeds from natural stands of the goldfields area yielded the lowest kernel weight from whole seeds (Sample 1, Table 2). In a typical commercial seed-grading operation these seeds would have been selected as being of acceptable quality. Their size and weight are similar to many higher-yielding seeds from the wheatbelt region; the only difference was their appearance, which may not be considered important in an industrial-scale operation. Other than the goldfields sample, most of the other seeds had a similar kernel yield. A slightly lower kernel yield was found in seeds from
Quairading (Sample 2) stored for 42 months (Table 1). A high yield of the kernel was given by the Perth metropolitan sample (Sample 7) which was grown in a coastal sandy soil (Table 2). Although this is not a natural habitat for $S$. spicatum these plants and their host trees are well-maintained and irrigated.

The smallest seed fraction (diameter $<14 \mathrm{~mm}$ ), usually $\leq 2 \%$ of the total collected seeds, is generally discarded in selecting seeds for plantations as this fraction creates difficulties in the de-shelling process. Smaller seeds have a thicker shell (pericarp), making it difficult to use a process designed to break the shell yet not crush the kernel. Severely damaged kernels can hinder the separation process and promote oxidation and fungal growth.

\section{Oil yield and moisture of seed kernel}

Differences in kernel weight among the samples had no significant effect on the relative weight loss on drying (Table 3). Contrary to loss-on-drying results, substantial differences were recorded between seed lots in oil yield. Larger seeds from the wheatbelt region were found to contain more oil. Least yield was recorded in the one seedlot from the goldfields (Sample 1). This seedlot was also the lowest in kernel percentage (w/w). The sample from Perth (Sample 7) was found to contain the lowest oil yield in comparison to kernel yield. Plantation-grade seeds collected from the Quairading area in 2006 and 2009 had a 5\% difference in oil yield favouring the 2006 collection (Table 3).

\section{Fatty acid content of seed oil}

The fatty acid profiles of the seed oil (Table 4) were remarkably constant. Ximenynate (XYMA) and oleate were the major fatty acids species found in the lipid fraction. As ximenynate (transximenynic acid) is a unique fatty acid found thus far in only two genera of the plant kingdom (Santalum and Ximenia), its occurrence in sandalwood seed is of particular interest.

Table2 Whole-seed and kernel diameter data, and yield

\begin{tabular}{|c|c|c|c|c|c|}
\hline \multirow[b]{2}{*}{ Code } & \multicolumn{2}{|c|}{ Seed } & \multicolumn{2}{|c|}{ Kernel } & \multirow{2}{*}{$\begin{array}{c}\text { Kernel weight/ } \\
\text { seed weight } \\
(\%)\end{array}$} \\
\hline & $\begin{array}{l}\text { Diameter } \\
(\mathrm{mm})\end{array}$ & $\begin{array}{l}\text { Weight } \\
\text { (g) }\end{array}$ & $\begin{array}{l}\text { Diameter } \\
(\mathrm{mm})\end{array}$ & $\begin{array}{l}\text { W eight } \\
\text { (g) }\end{array}$ & \\
\hline Sample 1 & $17.70 \pm 1.46$ & $2.29 \pm 0.54$ & $8.59 \pm 2.03$ & $0.40 \pm 0.21$ & 17.47 \\
\hline Sample 2 & $17.58 \pm 1.55$ & $2.45 \pm 0.56$ & $11.21 \pm 0.95$ & $0.74 \pm 0.17$ & 29.13 \\
\hline Sample 3 & $21.70 \pm 2.58$ & $4.04 \pm 4.04$ & $14.07 \pm 2.17$ & $1.39 \pm 0.60$ & 34.41 \\
\hline Sample 4 & $17.32 \pm 2.54$ & $2.24 \pm 0.87$ & $11.54 \pm 1.48$ & $0.79 \pm 0.34$ & 35.27 \\
\hline Sample 5 & $12.85 \pm 0.94$ & $1.02 \pm 0.28$ & $8.57 \pm 1.28$ & $0.32 \pm 0.14$ & 31.37 \\
\hline Sample 6 & $18.81 \pm 1.63$ & $2.95 \pm 0.67$ & $12.50 \pm 1.23$ & $0.92 \pm 0.26$ & 31.19 \\
\hline Sample 7 & $19.14 \pm 2.03$ & $3.13 \pm 0.97$ & $12.95 \pm 2.69$ & $1.16 \pm 0.35$ & 37.06 \\
\hline
\end{tabular}

*V alues are reported as mean \pm standard deviation of 100 random seeds $(n=100)$

Table . oisture content and oil yield of seed kernel

\begin{tabular}{|c|c|c|c|c|c|c|c|c|c|c|c|c|c|c|}
\hline Property & \multicolumn{2}{|c|}{ Sample 1} & \multicolumn{2}{|c|}{ Sample 2} & \multicolumn{2}{|c|}{ Sample 3} & \multicolumn{2}{|c|}{ Sample 4} & \multicolumn{2}{|c|}{ Sample 5} & \multicolumn{2}{|c|}{ Sample 6} & \multicolumn{2}{|c|}{ Sample 7} \\
\hline oss on drying* $(\% \mathrm{w} / \mathrm{w})$ & 3.35 & 0.27 & 3.75 & 0.26 & 3.23 & 0.3 & 3.49 & 0.32 & 3.64 & 0.29 & 3.20 & 0.26 & 3.95 & 0.28 \\
\hline il yield * (\% w/w) & 35.50 & 5.24 & 52.55 & 7.75 & 47.98 & 7.08 & 37.31 & 5.50 & 42.03 & 6.20 & 40.28 & 5.94 & 38.07 & 5.62 \\
\hline
\end{tabular}


Table • atty acid content of seed oil

\begin{tabular}{|c|c|c|c|c|c|c|c|c|c|c|c|c|c|c|}
\hline \multirow{3}{*}{$\begin{array}{c}\text { atty acid } \\
\text { Palmitate }\end{array}$} & \multicolumn{14}{|c|}{ Composition of fatty acids (\% w/w) } \\
\hline & \multicolumn{2}{|c|}{ Sample 1} & \multicolumn{2}{|c|}{ Sample 2} & \multicolumn{2}{|c|}{ Sample 3} & \multicolumn{2}{|c|}{ Sample 4} & \multicolumn{2}{|c|}{ Sample 5} & \multicolumn{2}{|c|}{ Sample 6} & \multicolumn{2}{|c|}{ Sample 7} \\
\hline & 3.74 & 0.1 & 3.73 & 0.09 & 3.98 & 0.15 & 3.43 & 0.1 & 3.67 & 0.08 & 3.51 & 0.07 & 3.33 & 0.11 \\
\hline Palmitoleate & 0.43 & 0.06 & 0.55 & 0.06 & 0.60 & 0.04 & 0.53 & 0.07 & 0.54 & 0.05 & 0.47 & 0.02 & 0.48 & 0.07 \\
\hline Stearate & 1.79 & 0.05 & 2.31 & 0.06 & 1.78 & 0.08 & 1.81 & 0.05 & 2.05 & 0.06 & 1.57 & 0.03 & 2.09 & 0.07 \\
\hline leate & 52.88 & 1.21 & 54.45 & 0.91 & 50.27 & 0.87 & 50.13 & 0.74 & 53.53 & 0.95 & 48.80 & 0.65 & 48.74 & 0.84 \\
\hline inoleate & 1.45 & 0.06 & 1.23 & 0.05 & 1.57 & 0.10 & 1.25 & 0.06 & 1.11 & 0.8 & 1.20 & 0.1 & 1.15 & 0.07 \\
\hline inolenate & 3.74 & 0.11 & 2.15 & 0.1 & 2.93 & 0.17 & 2.95 & 0.14 & 2.19 & 0.15 & 3.35 & 0.14 & 2.44 & 0.13 \\
\hline rans-linolenate & 1.71 & 0.07 & 0.99 & 0.06 & 1.14 & 0.1 & 1.00 & 0.06 & 1.14 & 0.07 & 1.74 & 0.08 & 1.09 & 0.08 \\
\hline imenynate ( $\mathrm{Y}$ & 32.72 & 0.29 & 33.36 & 0.18 & 36.19 & 0.27 & 37.24 & 0.08 & 34.46 & 0.15 & 37.79 & 0.09 & 39.14 & 0.01 \\
\hline thers & 14.0 & 0.18 & 12.09 & 0.16 & 13.54 & 0.20 & 12.63 & 0.14 & 12.01 & 0.26 & 12.41 & 0.13 & 12.12 & 0.16 \\
\hline
\end{tabular}

XYMA has unique chemical and pharmacological properties as mentioned in the Introduction. The number of research and commercial investments in cosmetic and pharmaceutical uses of XYMA suggests that it should be in high demand in coming years. WA sandalwood seed oil is likely to be the only plentiful source of XYMA. From an industrial point of view, only seeds that are rich in XYMA are viable as a commercial product. All our samples are rich in XYMA and could in future be a good source of this valuable fatty acid.

The main fatty acid, oleate, is common in many vegetable oils, notably olive oil. It has been a good additive in many cosmetic and pharmaceutical formulations. Sandalwood seed oil has a low concentration of saturated fatty acids, which is seen as a positive indicator from a health perspective. Moreover, the low concentrations of polyunsaturated fatty acids will benefit the oxidative stability of this oil.

\section{Discussion}

Seeds from sandalwood plantations are now available in the wheatbelt region of WA in quantities larger than can be used in the limited market for novelty nuts. Planters and rural communities could benefit by establishing an industry based on these seeds. The seed oil is seen as a unique product from Australia by global cosmetic and pharmaceutical markets. Our initial approach to these prospects was to find and evaluate raw material sources for the sandalwood seed oil industry.

This assessment provides an evaluation of the quality of sandalwood seed oil with respect to seed quality as evaluated by kernel yield, oil yield, moisture content and the fatty acid profile. This study documents suitable sources of sandalwood seeds that would cater for a future industry. Parameters considered here may define standards for raw material quality assurance for a future seed oil industry.

Kernel weight as a fraction of seed weight was an important parameter to be considered for industrial processing and was employed to predict raw material yield from whole seeds. Seed outer diameter correlates with kernel yield for commercial plantations in the wheatbelt area, but not for native trees in the goldfields (Table 2). It was found that the current procedures used by planters are suitable for initial grading of raw material for oil production.
In this study sandalwood seeds have been shown to have a promising oil content. High oil content is conducive to commercial gain. Seeds from plantations in the wheatbelt region had higher yields, while seeds from the goldfields and the coast (Perth) had lower ones. In the Perth and Quairading 2009 seed lots, oil yield was not consistently greater in larger nuts. This could be due to variation in the carbohydrate and protein content compared with the lipids. Geographic, nutritional and climatic factors may influence seed oil formation. Certain conditions may diminish lipid synthesis while other constituents relatively increase, producing heavier kernels with less oil. For an industrial product, variability in oil yield is economically significant. Samples analysed in this study did not reveal large variation in the concentration of XYMA and/or compounds of other fatty acids. The fraction of XYMA present in the oil is an important parameter as this oil is a rare source of this fatty acid. All the samples fell within the previously published range for XYMA concentration. It is also evident that storage time has no significant affect on quality parameters or the oil content.

With high yields and desired fatty acid composition; it could be concluded that seeds which are currently available in abundance from the sandalwood plantations in the wheatbelt region of WA are a suitable and a viable source of raw material for a future seed oil industry.

\section{Acknowledgement}

The authors are pleased to acknowledge the support and technical facilities provided by staff and management of Wescorp Sandalwood Pty Ltd, and the seed samples provided for the study by Mr Gordon Taylor and Mr Grant Pronk.

\section{References}

AOCS (2009) Method Ab-49. Official methods and recommended practices of the AOCS. AOCS Press, Danvers, MA, USA.

Barrett, D.R. and Fox, J.E.D. (1995) Geographical distribution and botanical characteristics of species in the genus Santalum. In: Gjerum, L., Fox, J.E.D. and Ehrhart, L. (eds) Sandalwood Seed Nursery and Plantation Technology. Field Document No. 8. RAS/92/361: 3-23, FAO, Suva, Fiji.

Bombardelli, E., Guglielmini, G., Morazzoni, P., Curri, S.B. and Polinelli, W. (1994) Microvasculokinetic activity of ximenynic acid ethyl ester. Fitoterapia 65, 195-201. 
Christie, W.W. (1993) Advances in Lipid Methodology. Oily Press, Dundee, UK.

Christie, W.W. (2007) Chromatographic analysis of lipids. In: Gunstone, F.D., Harwood, J.L. and Dijkstra, A.J. (eds) Lipid Handbook. CRC Press, Boca Raton, USA, pp. 426-455.

Clarke, M. (2006) [An overview and analysis of research interests.] In: Australia's Sandalwood Industry. RIRDC, Canberra, Australia, pp. 15-23.

Fox, J.E.D. (1992) Where to with sandalwood? Annual Symposium of the Western Australian Branch, Australian Institute of Agricultural Science, 25th September 1992, Nedlands, Western Australia.

Fox, J.E.D. (2000) Sandalwood: the royal tree. Biologist 47, 31-40.

George, A.S. (1984) Flora of Australia. Rhizophorales to Celastrales. Genus 9: Santalum. Australian Government Publishing Service, Canberra, Australia. Volume 22, 961-966.

Hatt, H.H. (1956) Some seed fats of the Santalaceae family. Journal of the Science of Food and Agriculture 7, 130-131.

Hettiarachchi, D.S., Liu, Y., Fox, J.E.D. and Sunderland, V.B. (2010). Western Australian sandalwood seed oil: new opportunities. Lipid Technology 22, 27-29.

IUPAC (1987) Standard Methods for Analysis of Oils. IUPAC Method 2.301. Blackwell Scientific Publications, UK.
Jones, P. (2002). Estimating Returns on Plantation-Grown Sandalwood (Santalum spicatum). Sandalwood Information Sheet, Forest Products Commission, Perth, Australia.

Jones, G.P., Watson, T.G., Sinclair, A.J., Birkett, A., Dunt, N., Nair, S. and Tonkin S.Y. (1999) Santalbic acid from quandong kernels and oil fed to rats affects kidney and liver P450. Asia Pacific Journal of Clinical Nutrition 8, 211-215.

Liu, Y.D. (1996) Separation and identification of ximenynic acid isomers in the seed oil of Santalum spicatum R.Br. as their 4, 4-dimethyloxazoline derivatives. Journal of the American Oil Chemists'Society 73, 1729-1731.

Liu, Y. and Longmore, R.B. (1997) Dietary sandalwood seed oil modifies fatty acid composition of mouse adipose. Lipids 32, 965-969.

Liu, Y., Longmore, R.B. and Fox, J.E.D. (1997) Proximate and fatty acid composition changes in developing sandalwood (Santalum spicatum) seeds. Journal of the Science of Food and Agriculture 75, 27-30.

McKinnell, F.H. (2008) WA Sandalwood Industry Development Plan 2008-2020. Forest Products Commission of Western Australia, Perth, Australia. 